\title{
Internal Audit and Review of the Negative Customer Behavior
}

\author{
Jing Wu \\ Department of Enterprise Management, Management School, Jinan University, Guangzhou, China \\ Email: wujing781@163.com
}

Received 3 July 2015; accepted 11 August 2015; published 14 August 2015

Copyright (C) 2015 by author and Scientific Research Publishing Inc. This work is licensed under the Creative Commons Attribution International License (CC BY). http://creativecommons.org/licenses/by/4.0/

(c) (i) Open Access

\begin{abstract}
Negative customer behavior is a relatively new research field of marketing and management studies, and it is also a new perspective of service management in recent years. But diverse appellation and definition hinder its further development. This paper cardings and summarizes the research findings about many negative customer behaviors both in China and abroad. On the basis of clarifying the term evolution, we analyzed the cause of negative customer behavior from customer characteristics, marketing agency and consumer scenarios, and illustrated the negative effects both on employees' job performance and on other customers. We found that demographic characteristics, personality traits and situational awareness had important effects on negative customer behavior. Negative customer behavior not only brought pressure, emotional exhaustion, service failure, high absenteeism and turnover intention for employees, but also decreased the other customers' repurchase intention and satisfaction by emotional contagion. We made a forecast and expectation of the future research and pointed out that we should make further research according to China's service industry.
\end{abstract}

\section{Keywords}

Negative Behavior, Customer Behavior, Review

\section{Introduction}

With the gap of the information asymmetry between consumers and enterprises increasingly narrows, there has been a great change in the traditional weak position of consumers in the market, coupled with the current expansion of social egoism spread of ideas and consumer individualism [1]. Negative customer behavior is becoming a serious problem faced by many service-oriented businesses. In the interaction between customers and employees, some customers treat employee unfriendly attitude, verbal abuse or violence and bullying, damage to 
facilities, noisy, crowded, queue jumping and other acts [2]-[4]. They have not only a negative impact on business management and the customer service experience, but also great harm to physical and mental health of employees [5].

However, as the concepts "customer is God" and "the customer is always right" and other ingrained traditional concept shade; negative customer behavior is widespread; in practice, in order to please customers need, many enterprises did not give their full attention to release the harm to employee; in academia, although some progress has been made in research, most researchers concentrated on the theoretical discussion and the diversity define of negative customer behavior hindered its further development. Therefore, this article will clarify the confusing concepts and sorts out the integration of existing academic research results, thus, it provides the reference for the researchers to conduct the empirical study, to provide reference for managers to take management measures.

\section{The Evolution of Negative Customer Behavior}

The marketing literature has defined the negative customer behavior in many service interactions [2] [5]. And early studies focused primarily on oriented economic interests of negative customer behavior, Such as pilfering, unreasonable return and check fraud [6] [7]; In organizational behavior literature, the customer violated as an extension of workplace violations has also been widespread concern [8]-[10]. There are scholars studying immoral decision-making process from the view of social psychology [11] [12], from the perspective of organizational justice to study customer injustice [13] [14].

Because of the different view of scholars involved, names and definition of negative customer behavior is more diverse and even confusion. Such as George \&Dena (1989) use Deviant Consumer Behavior to definition of customer behavior of those who deviate from accepted norms [15]. Bitner \& Bernard (1994) called "problem customers" that who simply not cooperate, no willingness to cooperate, or a deliberate violation of the provisions of service place resulting in service personnel cannot provide a good quality of service [4]. Berry \& Seiders (2008) from the perspective of fairness to pointed that "customer injustice" refers to the customer not polite, irrational, don't respect the rights of others, making unfair, and other behavior to damage enterprise and employee (or other customer) [13]. Strutton \& David (1994) would be contrary to the widely accepted social standards of behavior as "Inappropriate Behavior" [16]. In addition, there are scholars named it "Unethical Consumer Behavior", "Uncooperative Customers”.

\subsection{Aberrant Consumer Behavior}

The related research of negative customer behavior started late at home and abroad, its systematic study began in the 1990s. Fullerton \& Punj (1993) is the scholars who first system research on negative customer behavior, they initially used the "Aberrant Consumer Behavior" to refer to the behavior contrary to accepted norms in exchange situation and gain extreme notoriety between businesses and most other customers; These behaviors are divided into three categories: disrupt facilities of service enterprises; caused abusive, threatening, physical or mental harm to other customers and employees; the material losses caused by various thefts, such as insurance, credit card, cheque fraud and shoplifting [5].

\subsection{Consumer Misbehavior}

With the increasing attention to the aberrant customer behavior, Fullerton \& Punj published a series of papers to encourage the academic to study aberrant customer behavior in deeply and widely exploration, and in 1997 the "Aberrant behaviors of customers" renamed "Consumer Misbehavior". They used standard expectation theory and labeling theory, pointed out that people would based on expect to form a common recognition and abide social norms, consumer behavior to affix the label whether or not meets this specification, because the process is personal and dynamic with complexity and relativity. Therefore, it will only be broadly defined the consumer behavior as "a violation of accepted norms in the consumer context, and disrupt the expected order in this situation.” [17] [18]. This definition emphasizes when customer behavior has been identified as improper that must be a violation of social norms and expectations. This definition is widely used in the follow-up study.

Subsequently, they summarized a series of research on their past and lists the range of Consumer Misbehavior. The list has 34 behaviors were divided into five types for the service employees, for goods and services, for other customers, for corporate financial assets and tangible or intangible contract [17] [18]. 


\subsection{Jaycustomer Behavior}

Lovelock (1994) using "Jaycustomer behavior" calling customer behavior of those who deliberately to imprudence or insulting behavior cause trouble to service enterprises, employees and other customers [19]. According to the nature of the bad behavior will be divided into customer theft who does not pay the cost of services (thief), loud noises militant type of customer (belligerent), often noisy infighting type of customers (family feuders), type of customer who damage service rules (rule breaker), type of customers who destruction of facilities (vandals), bad credit deadbeat type of customers (deadbeat), etc.

\subsection{Dysfunctional Customer Behavior}

Harris \& Reynolds (2003) had used Lovelock's concept, with the critical incident method to get eight types of jaycustomer behavior in the catering industry: the author of compensation letter, bad customer, property abusers, service workers use of their own advantages to steal enterprise benefit, retaliatory customer, verbal abusers, physical abusers, sex offenders, and analyzes the economic and non economic motivation who take these behaviors [2]. But later in the study, Harris\& Reynolds (2004) prefer these actions named "Dysfunctional Customer Behavior", and clearly defined it as: in the exchange situation, the customer who intentionally or unintentionally, publicly or secretly disrupting service contact function [20]. The definition combines Fullerton \& Punj violates norms and two core concepts of intention which Lovelock emphasizes, he does not give a clear negative meaning and it is a more neutral words. Youjae Yi \& Taeshik Gong (2008) also used the concept of "dysfunctional customer behavior", but its definition is the thoughtless or abuse behavior that cause problems to the service organization, employees and other customer, such as theft, fraud, intentional destruction, violence, revolt, abuse, physiological and psychological harm [21]. The definition is defined from the perspective of the causes and results, not emphasizes the characteristics of intention and destruction specification.

\subsection{Customer Mistreatment}

Bies (2001) from the perspective of interpersonal interaction justice defines customer mistreatment behaviors, the definition is "employee who suffered from low quality interpersonal treatment of customers, including rude, insulting and unreasonable or violated manner treat employees" [22]. Skarlicki \& Walker (2008) in their subsequent studies defined it as "it is interpersonal injustice that caused by a customer do not respect and damage the personality of the staff” [23].

From the perspective of the evolution of appellation of negative customer behavior, although different scholars use different names, yet as a negative customer behavior has two distinct features. First, the behavior imposed by the customer, the object may be a service employee, organization, or other customers, including the violation of social norms, violating the interests of others as well as conduct detrimental to the personality of others. Second, the implementation of behavior can be either due to intentional or innocently, but it will cause some damage. Customers are likely because of dissatisfaction with the service or the environment, also has the possibility is due to its own factors that implementation of such behavior, but often result in negative influence.

\section{Study on the Causes of Negative Customer Behavior Based on the Customer's Own Characteristics}

The reason of behavior happen is a focus for negative customer behavior research, to explore the causes of negative customer behavior can contribute to the organization's management to take specific measures to stop such behavior. A variety of reasons caused negative customer behavior. Fullerton \& Punj's article published in 2004 is more representative. Based on abnormal behavior in existing of sociology, criminology and psychology research article, which provides a basic interaction structure model to explain the negative customer behavior and in detail explain the misconduct motivations, including the presence of unmet expectations of consumers, in order to seek stimulation with abnormal way, the lack of moral restraint, special alliance (mainly refers to criminal gangs composed of young people), the existence of different social strata, provocation, opportunistic calculation. He pointed out that it is the interaction of these internal and external factors that have an impact on negative behavior, sometimes a prevail factor causing the customer negative behaviors, sometimes one factor to offset other factors that prevent the occurrence of this behavior.

Synthesizing the research results of scholars, the reason of negative customer behavior can be grouped into 
two categories: one is the consumer's own characteristics, the other one is the marketing agency and consumer scenarios. From the perspective of the consumer's own characteristics, research on the bad customer's behavior affects variables main draws theory and research from psychology, sociology and criminal psychology, and other related subjects.

\subsection{The Demographic Characteristics of the Customer Have the Obvious Difference in the Occurrence of Negative Customer Behavior}

In terms of age, Fullerton \& Punj (1993) pointed out that adolescents are usually more prone to violence and flagrant bold behavior than adults, so there are more shoplifting, vandalism records; Adults have more experience and opportunities than teenagers, therefore appears more insurance and credit card fraud [5]. Baron (1999) study shows that younger employees (19 - 24 years old) more frequently to take aggressive behavior than older employees (35 years), possible explanation is that the age of the elderly to better understand the consequences of violent behavior and has a strong emotional control [24].

Terms of gender, in the social and behavioral science research, the most consistent finding is that male customers are more likely to use violent behavior than female customers. Chen Xiaogui (2009) using single factor analysis of variance to verify the men in public to express their discontent more is calm than women and have more strongly willingness to take some actions; While many women are more sensitive to social condemnation, once they have made some really bad behavior, women are more likely to feel guilt, anxiety and worry than men and these emotions may prevent them from taking bad behavior [25]. Xu Yu (2010) through the research of high Stars Hotel in Changsha has shaped the image of common problems customer: slightly more male, aged between 30 - 44 years old, usually 3 - 5 peers, quite consumption experience and higher incidence in the restaurant, front desk and other departments [26].

Socioeconomic status often reflected through education, income and occupation (Daunt \& Harris, 2011) [27]. Chen Xiaogui (2009) study found that a higher level of education, engaged in the mental labor class, often morality and relatively high personal qualities and less prone to bad behavior [25]. Fullerton \& Punj (1993) argued that people of all income levels are likely to implement customer mistreatment, but their motives may be different (greed vs. basic needs), high level of education may increase the complexity of the incidence of violent behavior, such as credit card and check fraud are usually by better educated personnel who have the ability to achieve [5].

\subsection{The Personality Characteristics of Customer Showed Distinct Personal Characteristics in the Event of a Negative Customer Behavior}

Negative customer behavior may be due to either customer dissatisfaction with service or service environment and may also be determined by personal characteristics, such as selfishness, angry personality traits, neuroticism, perfectionism, etc. [9]. Previous studies showed that people with certain personality traits are more likely to implement negative customer behavior [24] [28]. If people have anger and aggressive personality traits tend to have higher levels of interpersonal irritability which are more inclined to carry out various forms of attack provocative behavior.

\subsection{Customer's Perception of Situational Play a Great Impact on Negative Customer Behavior}

Youjae Yi \& Taeshik Gong (2008) uses the social exchange theory and frustration aggression theory, through two rounds of research survey to MBA students of a university and customers of a manufacturing company in South Korea that found customers unfair feeling through the intermediary role of negative emotions that cause negative customer behavior [21]. Jin Liyin (2006) based on Service Justice Theory to construct a structure equation model for the interpretation of the bad customer behavior, tested by survey data from education and training services industry and found that three aspects of service justice perception not only through two intermediary variables of emotional reactions and psychological commitment affect the negative customer behavior, but also the service interactive justice perception will have direct effect on negative customer behavior [1]. Liu Li \& Li Xiaojun (2013) pointed out that fair perception and attribution style of customer have interaction effects; He designed four service unfair experimental situation, (the result is not fair/unfair process) $\times$ attribution (controllable/ 
uncontrollable), through the analysis of variance found that when causes of service unfair events controllable, customer perceived process unfair more easily cause customer badness behavior occurs than customer perceived results unfair [29]. Customer perceived justice and attribution in the service process can generate negative emotion which leads to negative customer behavior.

To some extent, customer injustice to enterprise or service personnel also stems from the imbalance of power in service environment. Based on Emerson power-dependence theory, A to B power size, equal to B of the A dependence on the size. Unequal power may lead to unfair communicative behavior of customers. Therefore, Gong Jinhong (2011) pointed out that some customers that use unequal power to make social etiquette breach of the general demeanor, and even abuse of power. Customers use their right to speak, deliberately complaint service personnel, reasonable claim etc [30]. Yagil (2008) reviewed about the customer verbal abuse and sexual abuse of the previous studies that get a similar conclusion: when the service provider status is low and excessive dependence on customers, more possibility of customer inappropriate behavior occur [31].

Unbalance of rights derived from the "customer is God" the long-term effects of this kind of slogan, which leads to customer expectations for their role in the service process. Gong Jinhong (2011) by the method of content analysis confirmed that some customers may have their role too much or excessively reduce the role of the status of service personnel, thus happen mismatch service, unreasonable demands and lack of respect for employees, deliberately make things difficult for employees and other negative behavior [30]. Chen Xiaogui (2009) also pointed out that between the customer and the enterprise had a microsecond and subtle mutual expectations, it is "Psychological contract "in organization behavior science; once violation of customer's psychological contract, the customer will show complaint behavior, dissatisfaction, or cause adverse customer behavior [25].

Customer dissatisfaction with service contact is one of the direct causes of negative customer behavior. Reynolds \&Harris (2009) on the basis of literature studies that summed three constructs included dissatisfaction with the services and Dysfunctional Customer Behavior; through the empirical research shows that customers more dissatisfied with the service, the more severe Dysfunctional Customer Behavior [32]. Richins (1983) also pointed out that when customer dissatisfaction with service staff that will produce unpleasant emotional reaction, serious misconduct will be implemented, such as the type of abuse [33].

\section{Based on Marketing Agency and Consumer Scenario to Study the Causes of Negative Customer Behavior}

From the perspective of marketing agencies and consumer scenarios, scholars use the service contact theory, situational theory to explore the causes of negative customer behavior.

\subsection{Organization to Excessive Tolerance of Negative Customer Behavior Which Improve the Occur Chances}

The philosophy of "Customer is God" was widely recognized by service-oriented organization and as an inherent part of employee in routine service work [34]. When the organization over tolerate to customers that negative customer behavior are more likely to occur (Including that "the customer is always right", ignoring the customer misconduct, in the service encounter process make customers have illusion that they can control the relationship between them and service employee). Bishop \& Korczynski (2005) found that in a study about the violence in the service industry: although service staff suffering customer's violence, the organization's management is often denied and often convey reasons to staff that this phenomenon is caused by the staff themselves who provide poor service, so it’s their responsibility [35].

\subsection{The Consumption Environment Discomfort to Be an Incentive of Negative Customer Behavior}

Some foundation marketing research through system record varieties of consumers' perception and behavior attribution that confirm the design environment component can affect consumer behavior [36]. The pressures caused by environmental include: uncomfortable temperatures, insufficient light, low air quality and high noisy, crowded.

Rose \& Neidermeyer (1999) found that in retail service place the degree of noisy, waiting for time served, and even indoor temperature and the music and other factors that enterprise can control which influence the happen 
frequency and degree of customer's aggressive behavior, such as destruction of service facilities [37].

James \& Sevgin (1990) discuss controlling crowding degree and the background music size of retail stores in the experiment and exploring their influence on customer behavior; The results found that when music sound loud and crowded degree high which can increase the consumers' crowding perception to store [38].

Guo Na (2010) dividing customer bad behavior in the retail into four categories: aiming at the supermarket goods, the supermarket staff, other consumers and service facilities and environment of supermarket; she found that it has certain relevance between customer bad behavior and situational factors of supermarket, such as supermarket decoration quality, merchandise display layout, the staff working efficiency and service attitude [39].

\section{Influence of Negative Customer Behavior}

Although study on the effects of customer behavior relatively more, yet the research to system reveals the influence of customer misconduct less. Harris \& Reynolds (2003) through the depth interview of the customer, the front desk staff and management personnel that for the first time use qualitative method to systematically analysis the impact of customer misconduct behavior, they found that customer misconduct behavior will not only result in anxiety, insomnia and other long-term psychological problems to the service staff, and fear, stress, frustration, anger, resentment, worry and other short-term emotional response; but also will destroy other customer's consumption experience and have a "domino" effect on other customers which resulting in the spread of customer misconduct and causing direct and indirect economic losses to the service organization [2]. In addition to the qualitative research of Harris \& Reynolds, some scholars have used quantitative research methods revealed certain aspects of influence caused by negative customer behavior.

\subsection{Negative Customer Behavior Has a Negative Impact on the Performance of the Service Staff}

Liu Xiaoyu (2012) investigated the effects of sexual harassment on the customer service performance which found employees who suffer sexual harassment would difficult to comply emotions codes and have negative effects on employee performance [40]; Grandey (2004) and Li Xiaoyans' (2012) studies have proved the customers' rhetoric violations (yelling, insults, curses violations, etc.) have negative impact on the pressure, emotional exhaustion, absenteeism, turnover intention of the staff [41] [42]. Ruhama (2011) study shows that the more happy employees are more easily influenced by customer aggression, the reason may be that happy employees more customer-oriented and pay more friendly help, once the customer has been violated will considers that unworthy or unfair, which suffered greater damage than unhappy employees [43].

$\mathrm{Xu}$ Yang (2013) conducted a questionnaire survey to taobao.com online customer service employee and find between customer injustice and customer service staff job burnout (emotional exhaustion, be cynical, and low sense of achievement) have positive correlation, and the lower the emotional intelligence of customer service, the more significant of this relationship [44]; Zhang Xiujuan (2008) on the basis of emotional events theory and moral fairness theory found that customer unfair behavior often offset positive emotions by negative emotions and thus have indirect affect on job performance of customer service employee; this conclusion is different from the traditional perception that "employees' negative customer behavior will produce negative emotions which directly affect employees performance" [45]. Xie Lishan (2011) found in a series of studies that customer unfair behavior will make employees have emotional labor, but the employee empathy play a moderating role, namely employee empathy ability stronger, customer injustice on employees' negative emotion influence smaller [46] [47].

Some scholars [23] [48] [49] to study the relationship between negative customer behavior and employees' retaliation/service damage, whose research from the perspective of moral identity, emotion theory, resource theory, supervisor support, organizational control level, etc. Unanimous conclusion is that the employees who suffered customer brutal treatment are likely to eliminate discomfort hearts by destroying the service delivery process or retaliation customer.

\subsection{Negative Customer Behavior Has Emotional Contagion Impact on Other Customer's Behavior}

Some scholars have pointed out that in the consumption situation when customers see other customer badness 
behavior, they will show some behavioral responses, such as withdrawal, venting, constructive suggestions, discouraging, understand, agree, revenge, sympathy employees, complaints, etc. Fan Guangwei (2010) developed a ten dimension customer reactions scale, the customer who in the same situation, and found that customers have diversity reaction to other customers' bad behavior, the possibility to take "revenge" and "complaints" behavior reaction is little, mostly choose silently "exit" the service enterprise [50]. Xiaosheng Nan (2012) found that customer who suffered interference of negative customer behavior that will generate anger and resentment, which anger has a significant impact on the complained behavior, which have no significantly impact on the negative word of mouth and loyalty and discontent will bring a significant reduction of loyalty [51].

However, some scholars have noted that the effects of violent behavior to the customer is not so simple, demographic variables, attribution style, relationship quality will have a regulating effect. Huang (2010) using the attribution theory to study the impact mechanism of customers bad behavior on other customer and found that when the customer think other customer s' rude behavior can be controlled by service enterprises, which will happen again in the enterprise, the customer tends to spread negative word of mouth and reduce the repurchase intention [52]. Zhang Guangling (2013) studies also support this view and point out that the attribution of responsibility for customer bad behavior will has the direct influence on repurchase behavior and exit behavior, which through the mediating effect of customer dissatisfaction and have the indirect impact on customer to imitate the bad behavior; she also pointed out that the relationship quality play a regulatory role and to some extent the trust relationship can ease the customer dissatisfaction, which reducing the tendency of customers withdraw from the enterprise or imitate the bad behavior and increase the possibility of customer repurchase [53].

\section{Conclusions and Future Research}

For more than 20 years, the research of negative customer behavior mainly concerns the concept, type, effect, influence factors, management strategies and other aspects. Although the scholars have researched on the negative customer behavior in the theory and empirical research, yet there are still many problems to be explored in depth. According to the research context of negative customer behavior, the following areas needed to be improved and will be the focus of negative customer behavior in future research.

\subsection{Negative Customer Behavior Scale Study Provide System Context for the Connotation of the Concept of Negative Customer Behavior}

Due to the form and degree of negative customer behavior diversity which have challenges to systems measure it, so far, domestic and foreign scholars have not yet developed a mature negative customer behavior scale with good reliability and validity. Only a few scholars developed investment scales for specific customer negative behavior which greatly restricted the in-depth study of negative customer behavior. Therefore, the developing, testing and refining of overall scale of negative customer behavior are needed to be carried out urgently which is the basis to the system. They clarify the concept and the connotation of negative customer behavior.

\subsection{Integrated Multidisciplinary Research Perspective Made Theoretical Foundation for Negative Customer Behavior Study}

In future studies, theories and methods of psychology, sociology, marketing, criminology are needed to be further referenced. From the psychological perspective, the emotions and the personality impact on the negative customer behavior and their relationship between each other are researched. The sociological conflict theory and social exchange theory are used to explain the negative customer behavior interaction system, psychological contract violation and other phenomena. This can lay the theoretical foundation for negative customer behavior research.

\subsection{The Research Situation of Multi Culture Background Strengthen the Effectiveness of Management Strategies of Negative Customer Behavior}

People in different countries or regions have different cultural backgrounds, which will cause different orientation values and behaviors. So the reasons of negative customer behavior are different. With the cross-cultural services have become increasingly frequent in the world, it has a great practical significance to research customers' specific psychology and ideology with different cultures. 
The research of current management strategies of the negative customer behavior which is mainly based on the effects and influence factors puts forward some management recommendations. For example, Fullerton \& Pun (1997) analyzed the advantages and disadvantages of "deterrence" and "education" and pointed out that companies took the corresponding countermeasure according to the causes of the improper behavior [18]. Berry \& Seiders (2008) pointed out that managers could emphasize customer behavior norms to enhance customer perception of fairness and give different treatments to different customers to manage customers' inappropriate behaviors [13]. The research goal of the negative customer behavior is to prevent and reduce its adverse impact affect. Therefore, the researchers should pay great attention to the research on the management strategy of the negative customer behavior.

\section{References}

[1] Jin, L.Y. (2006) A Study on Customer Badness Behavior Model Base on Service Justice. Journal of Marketing Science, 2, 1-13.

[2] Harris, L.C. and Reynolds, K.L. (2003) Jaycustomer Behavior: An Exploration of Types and Motives in the Hospitality Industry. Journal of Services Marketing, 18, 339-357. http://dx.doi.org/10.1108/08876040410548276

[3] Zemke, R. and Anderson, K. (1990) Customer from Hell. Training, 27, 23-25.

[4] Bitner, M.J., Booms, B.H. and Mohr, L.A. (1994) Critical Service Encounters: The Employee’s Viewpoint. Journal of Marketing, 58, 95-104. http://dx.doi.org/10.2307/1251919

[5] Fullerton, R.A. and Punj, G. (1993) Choosing to Misbehave: A Structural Model of Aberrant Consumer Behavior. Advances in Consumer Research, 20, 570-574.

[6] Kallis, M.J. and Vanier, D.J. (1985) Consumer Shoplifting: Orientations and Deterrents. Journal of Criminal Justice, 13, 459-473. http://dx.doi.org/10.1016/0047-2352(85)90045-5

[7] Hart, C.W.L. (1993) Extraordinary Guarantees: A New Way to Build Quality throughout Your Company \& Ensure Satisfaction for Your Customers. Academy of Management Perspectives, 7, 93-95. http://dx.doi.org/10.5465/AME.1993.9503103259

[8] Aquino, K. (2000) Structural and Individual Determinants of Workplace Victimization: The Effects of Hierarchical Status and Conflict Management Style. Journal of Management, 26, 171-193. http://dx.doi.org/10.1177/014920630002600201

[9] Bedi, A. and Schat, A.C.H. (2007) Customer Aggression: A Theoretical and Meta-Analytic Review. ASAC, 28, 115128.

[10] Glomb, T.M. and Liao, H. (2003) Interpersonal Aggression in Work Groups: Social Influence, Reciprocal, and Individual Effects. Academy of Management Journal, 4, 486-496. http://dx.doi.org/10.2307/30040640

[11] Ford, R.C. and Richardson, W.D. (1994) Ethical Decision Making: A Review of the Empirical Literature. Journal of Business Ethics, 13, 205-221. http://dx.doi.org/10.1007/BF02074820

[12] Babakus, E., Cornwell, T.B., Mitchell, V. and Schlegelmilch, B. (2004) Reactions to Unethical Consumer Behavior across Six Countries. Journal of Consumer Marketing, 21, 254-263. http://dx.doi.org/10.1108/07363760410542165

[13] Berry, L.L. and Seiders, K. (2008) Serving Unfair Customers. Business Horizons, 51, 29-37. http://dx.doi.org/10.1016/j.bushor.2007.09.002

[14] Rupp, D.E. and Spencer, S. (2006) When Customers Lash out: The Effects of Customer Interactional Injustice on Emotional Labor and the Mediating Role of Discrete Emotions. Journal of Applied Psychology, 91, 971-978. http://dx.doi.org/10.1037/0021-9010.91.4.971

[15] Moschis, G.P. and Dena, C. (1989) Deviant Consumer Behavior. Advances in Consumer Research, 16, $732-737$.

[16] Strutton, D., Vitell, S.J. and Pelton, L.E. (1994) How Consumers May Justify Inappropriate Behavior in Market Settings: An Application on the Techniques of Neutralization. Journal of Business Research, 253-60. http://dx.doi.org/10.1016/0148-2963(94)90055-8

[17] Fullerton, R.A. and Punj, G. (1997) What Is Consumer Misbehavior. Advances in Consumer Research, 24, 336-339.

[18] Fullerton, R.A. and Punj, G. (1997) Can Consumer Misbehavior Be Controlled? A Critical Analysis of Two Major Control Techniques. Advances in Consumer Research, 24, 340-344.

[19] Lovelock, C. (1994) Product Plus: How Product + Service = Competitive Advantage. McGraw-Hill, New York.

[20] Harris, L.C. and Reynolds, K.L. (2004) The Consequences of Customer Dysfunctional Behavior. Journal of Service Research, 6,144-161. http://dx.doi.org/10.1177/1094670503257044 
[21] Yi, Y. and Gong, T. (2008) The Effects of Customer Justice Perception and Affect on Customer Citizenship Behavior and Customer Dysfunctional Behavior. Industrial Marketing Management, 37,767-783. http://dx.doi.org/10.1016/j.indmarman.2008.01.005

[22] Bies, R.J. (2001) Advances in Organizational Behavior. Stanford University Press, Stanford, 89-118.

[23] Skarlicki, D.P., van Jaarsveld, D.D. and Walker, D.D. (2008) Getting Even for Customer Mistreatment: The Role of Moral Identity in the Relationship between Customer Interpersonal Injustice and Employee Sabotage. Journal of Applied Psychology, 93, 1335-1347. http://dx.doi.org/10.1037/a0012704

[24] Baron, R.A., Neuman, J.H. and Geddes, D. (1999) Social and Personal Determinants of Workplace Aggression: Evidence for the Impact of Perceived Injustice and the Type A Behavior Pattern. Aggressive Behavior, 25, 281-296. http://dx.doi.org/10.1002/(SICI)1098-2337(1999)25:4<281::AID-AB4>3.0.CO;2-J

[25] Chen, X.G. (2009) Research of Customer Bad Behavior Based on Psychological Contract Violation. PhD Thesis, Guangdong University of Foreign Studies, Guangzhou, 54.

[26] Yu, X. (2010) A Study of the Problematic Customers’ Behaviors and Its Effects on the Employees. Journal of Beijing International Studies University, 179, 67-72.

[27] Daunt, K.L. and Harris, L.C. (2011) Customers Acting Badly: Evidence from the Hospitality Industry. Journal of Business Research, 64, 1034-1042. http://dx.doi.org/10.1016/j.jbusres.2010.10.010

[28] Inness, M., Leblanc, M.M. and Barling, J. (2008) Psychosocial Predictors of Supervisor, Peer, Subordinate, and Service Provider Targeted Aggression. Journal of Applied Psychology, 93, 1401-1411. http://dx.doi.org/10.1037/a0012810

[29] Liu, L. and Li, X.J. (2013) A Study on the Effect of Service Injustice and Attribution on Customer Badness Behavior. Market Modernization, 14, 57-58.

[30] Gong, J.H., Peng, J.M. and Xie, L.H. (2011) Customer Unfairness: Role Discrepancies and Power Imbalance. Commercial Research, 1, 174-179.

[31] Yagil, D. (2008) When the Customer Is Wrong: A Review of Research on Aggression and Sexual Harassment in Service Encounters. Aggression and Violent Behavior, 13, 141-152. http://dx.doi.org/10.1016/j.avb.2008.03.002

[32] Reynolds, K.L. and Harris, L.C. (2009) Dysfunctional Customer Behavior Severity: An Empirical Examination. Journal of Retailing, 85, 321-335. http://dx.doi.org/10.1016/j.jretai.2009.05.005

[33] Richins, M.L. (1983) An Analysis of Consumer Interaction Styles in the Market Place. Journal of Consumer Research, 10, 73-82. http://dx.doi.org/10.1086/208946

[34] Fullerton, R.A. and Punj, G. (2004) Repercussions of Promoting an Ideology of Consumption: Consumer Misbehavior. Journal of Business Research, 57, 1239-1249. http://dx.doi.org/10.1016/s0148-2963(02)00455-1

[35] Bishop, V., Korczynski, M. and Cohen, L. (2005) The Invisibility of Violence: Constructing Violence out of the Job Centre Workplace in the UK. Work, Employment and Society, 19, 583-602. http://dx.doi.org/10.1177/0950017005055671

[36] Eroglu, S.A. and Machleit, K.A. (1990) An Empirical Study of Retail Crowding: Antecedents and Consequences. Journal of Retailing, 66, 201-221.

[37] Rose, R.L. and Mandy, N. (1999) From Rudeness to Road Rage: The Antecedents and Consequences of Consumer Aggression. Advances in Consumer Research, 26, 12-17.

[38] McElroy, J., Morrow, P.C. and Eroglu, S. (1990) The Atmospherics of Personal Selling. Journal of Personal Selling and Sales Management, 10, 31-41.

[39] Guo, N. (2010) Customers’ Misbehavior Situational Factors Analysis and Management Measures in Retailing Industry. PhD Thesis, Northeastern University, Shenyang, 35.

[40] Liu, X.Y., Liu, J. and Guan, H.G. (2012) A Longitudinal Study on the Influencing Mechanism of Customer's Sexual Harassment on Front-line Employees’ Service Performance: The Moderating Roles of the Employee’s Traditionalism and the Team's Emotional Climate. Management World, 10,107-118.

[41] Grandey, A.A., Dickter, D.N. and Sin, H. (2004) The Customer Is Not Always Right: Customer Aggression and Emotion Regulation of Service Employees. Journal of Organizational Behavior, 25, 397-418. http://dx.doi.org/10.1002/job.252

[42] Li, X.Y. and Zhou, E.H. (2012) Influence of Customer Verbal Aggression on Employee Turnover Intention in a Service Business: Psychological Capital as a Moderator. Nankai Business Review, 15, 39-47.

[43] Goussinsky, R. (2011) Does Customer Aggression More Strongly Affect Happy Employees? The Moderating Role of Positive Affectivity and Extraversion. Motivation and Emotion, 35, 220-234. http://dx.doi.org/10.1007/s11031-011-9215-z 
[44] Xu, Y. (2013) A Research on Influence of Customer Injustice on Employee Job Burnout: Take Customer Service Staff as an Example. PhD Thesis, Nanjing University, Nanjing, 65.

[45] Zhang, X.J., Shen, W.G. and Chen, J.B. (2008) The Effects of Customers' Interactional Injustice on Employee' Performance: A Multi-Level Model. Nankai Business Review, 11, 96-103.

[46] Xie, L.S., Gong, J.H. and Liang, Y. (2011) Customer Injustice and on Employees Emotional Labor: The Role of Perspective Taking and Negative Affectivities. Chinese Journal of Management, 8, 720-726.

[47] Xie, L.S., Li, J.Y. and Zhang, C.L. (2011) A Study of Employees Perceived Customer Injustice: Exploratory Research Based on the Critical Incident Technique. Management Review, 23, 78-88.

[48] Wang, M., Liao, H., Zhan, Y. and Shi, J. (2011) Daily Customer Mistreatment and Employee Sabotage against Customers: Examining Emotion and Resource Perspectives. Academy of Management Journal, 54, 312-334. http://dx.doi.org/10.5465/AMJ.2011.60263093

[49] Yang, J.M., Ling, Y.L. and Huang, H.X. (2009) JayCustomer Behavior and Its Impacts on Frontline Employee’s Service Sabotage Intention. http://www.doc88.com/p-929288041003.html

[50] Fan, G.W. (2010) Research on Measurement of Customers’ Reactions to Other-Customer Misbehavior. PhD Thesis, Northeastern University, Shenyang, 25.

[51] Xiao, S.N. (2012) A Study on the Impact of Emotions Mediating Effect in Customers Misconduct—Based on the Fellow Customer's Perspective. Journal of Zhongnan University of Economics and Law, 5, 33-38.

[52] Huang, W.H. (2008) The Impact of Other Customer Failure on Service Satisfaction. International Journal of Service Industry Management, 19, 521-536. http://dx.doi.org/10.1108/09564230810891941

[53] Zhang, G.L., Wang, H. and Hu, Q.F. (2013) The Impact of Customers’ Misbehavior on other customer-Based on Attribution Theory. Journal of Wuhan University, 66, 90-95. 